\title{
JUVENILE IDIOPATHIC ARTHRITIS- A CLINIC-BASED STUDY
}

\author{
Suparna Guha1 ${ }^{1}$ Saheli Dasgupta², Sahar Ranjan Pal ${ }^{3}$, Indranil Das ${ }^{4}$
}

${ }_{1}^{1}$ Associate Professor, Department of Paediatric Rheumatology, Vivekananda Institute of Medical Sciences, Kolkata, West Bengal, India. 2Postgraduate Trainee, Department of Paediatric Medicine, Vivekananda Institute of Medical Sciences, Kolkata, West Bengal, India. 3 Professor, Department of Rheumatology, Vivekananda Institute of Medical Sciences, Kolkata, West Bengal, India. ${ }^{4}$ Assistant Professor, Department of Community Medicine, Vivekananda Institute of Medical Sciences, Kolkata, West Bengal, India. ABSTRACT

\section{BACKGROUND}

This is a clinic-based study conducted in the department of paediatric rheumatology at VIMS. We wanted to study the various types of JIA, their immunological characters and associated extra articular features, if any, in our paediatric rheumatology clinic at VIMS.

\section{METHODS}

A total of 30 patients with juvenile idiopathic arthritis were selected. They were divided into groups based on ILAR classification. Blood tests including complete blood counts, ESR, CRP, ANA (IIF Hep 2), HLA-B27 (PCR) were performed. Imaging consisted of MRI and Power Doppler USG.

\section{RESULTS}

Of the 30 cases, enthesitis related arthritis was commonest, followed by polyarticular variety. Males outnumbered females.

\section{CONCLUSIONS}

Juvenile idiopathic arthritis is the commonest cause of chronic arthritis in children. Contrary to other studies, enthesitis related arthritis was the most frequent in our cohort.

HOW TO CITE THIS ARTICLE: Guha S, Dasgupta S, Pal SR, et al. Juvenile idiopathic arthritis- a clinic-based study. J. Evolution Med. Dent. Sci. 2019;8(14):1150-1152, DOI: 10.14260/jemds/2019/255

\section{BACKGROUND}

Arthritis in children may be acute or chronic. The commonest cause of acute arthritis is infection(1), though trauma and malignancy especially leukaemia also may lead to acute inflammation of the joint cavity.(2) In the paediatric age group, the most common cause of chronic arthritis is juvenile idiopathic arthritis. If not diagnosed early and treated accordingly may lead to serious morbidity and deformities.(3,4)

\section{Aims and Objectives \\ The exact incidence and prevalence of JIA in eastern India is not known.(5) In our paediatric rheumatology clinic at VIMS we attempted to study the various types of JIA, their immunological characters and associated extra articular features if any.}

\section{METHODS}

The study was carried out in the paediatric rheumatology department of VIMS. The period of study was January 2013 to October 2014. It was a cross sectional retrospective study.

\section{Study Population}

The study population consisted of children less than 16 years of age having persistent joint swelling and movement restrictions which lasted more than 6 weeks. These children

'Financial or Other Competing Interest': None.

Submission 11-02-2019, Peer Review 26-03-2019,

Acceptance 01-04-2019, Published 08-04-2019.

Corresponding Author:

Dr. Suparna Guha,

Amartya Abasan, Flat No. 7, Building No. 8, Al Block, Sector 2,

Salt Lake City, Kolkata-700091, West Bengal, India.

E-mail: drs68guha@gmail.com

DOI: $10.14260 /$ jemds $/ 2019 / 255$

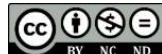

were divided into various groups according to ILAR (1) classification. 30 such patients were chosen.

\section{Inclusion Criteria}

1. Age-less than 16 years.

2. Sex- both males and females.

3. Joint swelling and movement restrictions.

4. Duration- more than 6 weeks.

\section{Exclusion Criteria}

Arthritis due to other inflammatory causes like malignancy, leukaemia, haemophilia, sickle cell anaemia were not included in our patient cohort.

Post Streptococcal Reactive Arthritis (PSRA) and post viral reactive arthritis whose symptoms lasted more than 6 weeks were included in the study as undifferentiated arthritis according to ILAR classification

A meticulous history and careful clinical examination were performed. Musculoskeletal examination and active joint count including DAS28 (15) and JADAS (16) were performed. A slit lamp examination of the eyes was performed and a thorough search for uveitis were carried out.

Investigation included routine blood counts, special serology like RF (Rheumatoid factor), ASO titre by latex agglutination ANA assay by immunofluorescence on Hep2 cells and HLA B27 by PCR.

Imaging studies included echocardiography, MRI and ultrasound power Doppler.

\section{RESULTS}

Out of the 30 patients who presented in our outpatient department, maximum number were Enthesitis related arthritis (ERA) whose count was 11, nine out of 30 patients had a Polyarticular variety, followed by 5 systemic onset or SOJIA, and only 3 oligoarticular or OJIA. 
Regarding undifferentiated variety there was 1 each of PSRA and post viral.

Regarding age of onset majority of our subjects had late onset (More than 10 years) excepting SOJIA where 1 child presented as early as 3 months of age.

Both the PSRA and post viral had an oligoarticular onset and median age of onset was same.

Regarding gender distribution, majority of our ERA and poly JIA had a male preponderance while females outnumbered males in OJIA and SOJIA types.

Regarding the growth parameters, as the children were suffering from a chronic inflammatory process majority had failure to thrive.

$50 \%$ had a stunted growth, height being less than $3^{\text {rd }}$ percentile for age(WHO criteria).Growth faltering was seen uniformly in all subtypes but maximum with SOJIA.

The active joint count depended on the age of onset and the subtype. Maximum inflamed joints were observed in SOJIA and Poly JIA variety.

Regarding the extra articular features, fever and rash was present in all the SOJIA patients. Fever was moderate to high grade and quotidian in nature. Rash was evanescent. 3 patients had generalised lymphadenopathy and hepatosplenomegaly.

Silent uveitis was present in 1 OJIA, while acute symptomatic uveitis was present in 1 ERA case.

1 Poly JIA was seropositive with high titre of RF positivity. Another Poly JIA had an overlap with dermatomyositis and high level of muscle enzymes. MRI showed muscle inflammation in T2 weighted image in this overlap case. ANA in high titre was present in 1 OJIA patient, who had silent uveitis.

USPD showed Enthesitis in 2 ERA patients. MRI done after 1 year follow up showed bilateral sacroiliitis in 2 cases of ERA.

Echocardiography showed grade 2 mitral. Regurgitation and grade 1 MVP (Mitral valve prolapse) n1 OJIA patient.

Grade 2 MR was present in 1 case of PSRA. None had any cardiovascular symptom.

\section{DISCUSSION}

Arthritis in children may be acute or chronic. The commonest cause of chronic arthritis in children is JIA.(6) Many studies have been conducted in various countries. But these epidemiological studies have shown conflicting results mainly due to diverse ethnicity and different study population (7-10). Although JIA is a rare disease, its true frequency is not known in our country. In the west its incidence is reported to be $6-8 / 100,000$ population per year.

\section{Our study on JIA patients highlighted the following features-}

1. Like other Indian studies. $(9,10)$ ERA variety was the commonest in our study. This was also reported by Aggarwal et al.(11) This was in contrast to a study conducted by Singh and colleges who reported oligoarticular variety to be commoner from the northern part of the country.(11) This was closely followed by polyarticular variety. Unlike North America and Europe where oligoarticular represents $50-75 \%$ cases of JIA, this variety was the least common in our study.
2. The mean age of onset in the west is usually $1-3$ years ${ }^{(10)}$ and rare below 6 months. The overall age of onset of disease in our study was 10-12 years, the adolescent age group. The mean age of onset was lowest in SOJIA, with the earliest case report being 3 months. In India JIA has a later age of onset. Such a similar observation was also reported by Kabra et al.( 9 )

3. Like other Indian studies our study too showed a male preponderance. Unlike most Indian observations however, OJIA and SOJIA showed a female predominance in our observation. The male preponderance of JIA in this part of the subcontinent may be due to the special characteristic of the disease seen in India; another explanation may be that boys in our country are cared more by family members and hence brought early for treatment.

Out of the 30 JIA subjects only in 2 uveitis could be picked up. One was OJIA with ANA + where the uveitis was completely asymptomatic, in fact the child had come to our clinic with only joint complaints. The other was an HLAB27+ ERA with acute anterior uveitis. This low incidence of uveitis could also be sighted in other Indian studies. Probably occurrence of uveitis is closely related to ANA+vity which is again reported to be very low in Indian children. In the western countries however, uveitis has been more frequently reported in JIA children.(12)

4. $\mathrm{RF}$ was positive in 1 child with Polyarticular involvement. RF + vity is seen only in $15-20 \%$ of JIA cases.(6) None of our children had rheumatoid nodules.

5. In our cohort the maximum incidence was of ERA. In fact 11 out of 30 cases were ERA. There are very few reports of JIA from eastern India. But in the study conducted by Ghosh et al(4) out if 50 children with JIA ony 2 had ERA. This was in contrary to our observation. But our observation was similar to other Indian studies.(13) Studies from the west (14) report that $6-19 \%$ of JIA cases are ERA. Out of 11 cases, only 1 was female and the rest males; majority were more than 10 years of age. Only one had a family history of spondyloarthropathy. Of the 11 cases of ERA, 7 had peripheral joint involvement at presentation. 4 had history of axial involvement in the form of low back pain. Enthesitis was present in 2 cases as demonstrated by USPD. 2 out of the 11 patients developed marrow oedema in MRI imaging, over 1 year follow up suggesting early sacroiliitis. This perhaps emphasises the need of early detection of sacroiliitis by MRI in children with low back pain in the background of a strong history and positive clinical examination. HLAB27+vity was present in 6 cases. This observation is at par with a study on ERA in Indian children by Agarwal. M et al which showed a higher proportion of HLAB27+VITY, early onset axial involvement, and paucity of family history, unlike their western counterparts.

Heart disease is a rare complication of JIA. None of the patients had any history of breathlessness or palpitations. Grade 2 MR was seen in the sole child with PRSA. In absence of any control group this finding cannot be taken as significant. 


\begin{tabular}{|c|c|c|c|c|c|c|c|c|c|c|}
\hline JIA & $\begin{array}{c}\text { Number of } \\
\text { Cases (\%) }\end{array}$ & \begin{tabular}{|c|}
$\begin{array}{c}\text { Male Female } \\
\text { Ratio }\end{array}$ \\
\end{tabular} & $\begin{array}{c}\text { Mean Age } \\
\text { of Onset }\end{array}$ & Rash & \begin{tabular}{|c|} 
Hepato- \\
Splenomegaly \\
\end{tabular} & Lymphadenopathy & Uveitis & \begin{tabular}{|c|} 
RA \\
Factor
\end{tabular} & ANA & $\begin{array}{l}\text { HLA } \\
\text { B-27 }\end{array}$ \\
\hline Polyarticular & $9(30)$ & $8: 1$ & & & & & & 1 & & \\
\hline SOJIA & $5(17)$ & All female & & 5 & 3 & 3 & & & & \\
\hline Oligoarticular & $3(10)$ & All female & & None & None & None & 1 & & 1 & \\
\hline ERA & $11(36)$ & $10: 1$ & & None & None & None & 1 & & & 6 \\
\hline PSRA & $1(3)$ & $\mathrm{F}$ & & None & None & None & & & & \\
\hline PVRA & $1(3)$ & $\mathrm{F}$ & & None & None & None & & & & \\
\hline
\end{tabular}

\begin{tabular}{|c|c|c|c|c|c|}
\hline Clinico-Immunological & Present Study & Singh et al & Casidy et al. & Seth et al. & Parkodi et al. \\
\hline M:F Ratio & & $1.8: 1$ & $1: 2$ & $1.3: 1$ & $1.6: 1$ \\
\hline Pauciarticular (\%) & 10 & 42.2 & 50 & 30 & 49 \\
\hline Polyarticular (\%) & 30 & 37.8 & 40 & 46 & 41 \\
\hline Systemic (\%) & 17 & 14.8 & 10 & 24 & 10 \\
\hline Rheumatoid Nodules (\%) & - & 5.4 & 10 & 0.8 & 3 \\
\hline Uveitis (\%) & 7.7 & 1.3 & 5 & 1.1 & 3 \\
\hline $\mathrm{ANF}^{*}(\%)$ & 3.8 & 0 & 45 & 6.5 & - \\
\hline Rheumatoid Factor* (\%) & 3.8 & 0 & 10 & 15 & 9.7 \\
\hline \multicolumn{6}{|c|}{ Table 2. Clinico-Immunological Profile of JIA in Other Studies } \\
\hline
\end{tabular}

\section{CONCLUSIONS}

JIA is the commonest cause of chronic arthritis in children. It has many types. Though OJIA is the predominant type in many parts of India, in our study ERA continues to be the main type. The limitations of the study were- small cohort and a short study period.

\section{REFERENCES}

[1] Kunnamo I, Kallio P, Pelkonen P, et al. Clinical signs and laboratory tests in the differential diagnosis of arthritis in children. Am J Dis Child 1987;141(1):3440.

[2] Brewer EJ Jr, Giannini EH. Standard methodology for segment I, II and III Pediatric Rheumatology Collaborative Study Group studies. I. Design. J Rheumatol 1982;9(1):109-3.

[3] Guidelines for the diagnosis of Rheumatic Fever. Jones Criteria, 1992. Special Writing Group of the Committee on Rheumatic Fever, endocarditis and Kawasaki Disease of The council on Cardiovascular Disease in the Young of the Ammerican Heart Association. Update JAMA 1993;269(4):476.

[4] Martel W, Holt JF, Cassidy JT. Roentgenologic manifestation of juvenile rheumatoid arthritis. Am J Roentgenol Radium Ther Nuci Med 1962;88:400-23.

[5] Sircar D, Ghosh B, Ghosh A, et al. Juvenile idiopathic arthritis. Indian Pediatrics 2006;43:429-33.
[6] Cassidy JT, Petty RE. Juvenile rheumatoid arthritis. In: Cassidy JT, Petty RE, eds. Textbook of Pediatric rheumatology. $3^{\text {rd }}$ edn. Philadelphia: WB Saunders Co. 1995: p. 133-223.

[7] Gare BA, Fasth A. Epidemiology of juvenile chronic arthritis in southwestern Sweden: a 5 year retrospective population study. Pediatrics 1992;90(6):950-8.

[8] Aggarwal A, Misra R. Juvenile chronic arthritis in India: is it different from that seen in Western Countries? Rheumatol Int 1994;14(2):53-6.

[9] Singh S, Salaria S, Kumar L, et al. Clinicoimmunological profile of juvenile rheumatoid arthritis at Chandigarh. Indian Pediatr 1999;36(5):449-54.

[10] Seth V, Kabra SK, Semwal OP, et al. Clinicoimmunological profile in juvenile rheumatoid arthritis - an Indian experience. Ind J Ped 1996;63(3):293-300.

[11] Aggarwal A, Misra RN. JRA in India: rarity of antinuclear antibody and uveitis. Indian J Pediatr 1996;63(3):301-4.

[12] Anderson GB, Fasth A. Incidence and prevalence of JRA. Annals of Rhematol 1987;46:277-81.

[13] Agarwal M, Jariwala M. 110 patients with ERA: a demographic and clinical study from a tertiary level pediatric rheumatology centre in India. Annals of Rheum 2012;71:264.

[14] Demirkaya E, Ozen S, Bilginer Y, et al. Distribution of JIA in the Eastern Mediterranean. Results from the Turkish registry. Clinical and Experimental Rheumatology 2011;29(1):111-6. 